\begin{tabular}{|c|l|}
\hline Title & Difficulty of discrimination modulates attentional capture by regulating attentional focus \\
\hline Author(s) & SAWA KI, Risa; KA TAY A MA, Jun'ichi \\
\hline Citation & $\begin{array}{l}\text { 47th annual meeting of the society for psychophysiological research, October 17-21, 2007, Hyatt Regency Hotel, } \\
\text { Savannah, Georgia, USA }\end{array}$ \\
\hline Issue Date & 2007-10 \\
\hline Doc URL & http://hdl.handle.net/2115/30151 \\
\hline Type & conference presentation \\
\hline File Information & 47 M MSPR4.pdf \\
\hline
\end{tabular}

Instructions for use 


\section{Difficulty of discrimination modulates attentional capture by regulating attentional focus}

Risa SAWAKI ${ }^{1,2}$ \& Jun'ichi KATAYAMA ${ }^{1}$

${ }^{1}$ Hokkaido University, JAPAN; ${ }^{2}$ Japan Society for the Promotion of Science (sawaki@edu.hokudai.ac.jp)

\section{Introduction}

P3a reflects the neural response regarding attentional capture for deviant events.

Attentional capture for distractor is enhanced by difficulty of discrimination between standard and target
in the three-stimulus oddball paradigm. Katayama \& Polich (1998); Sawaki \& Katayama (2006, 2007)

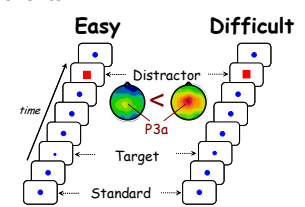

Purpose: to elucidate the cognitive mechanism of attentional capture modulation

Hypothesis: attentional capture is modulated by top-down controlled attentional focus. Attentional focus and cost-benefit

Spatial attention is tightly focused on a selective location

us processing.

BENEFIT: processing facilitation inside attentional focus COST: processing impairment outside attentional focus

In the difficult task, attention is sharply focused on the central location, and the distractor falls in this attentional focus (A). 〉> Attentional capture enhancement If so, when distractors are presented in the surrounding
location, distractors would fall outside the attentional focus in the difficult task (B)

>> Attentional capture attenuation

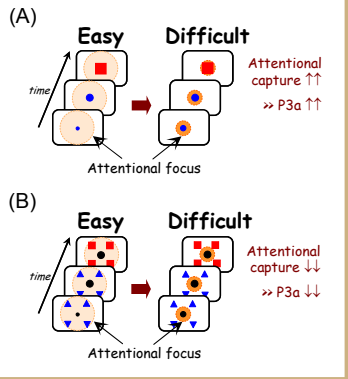

\section{Methods}

Participants: 12 students $(7 \mathrm{~m}, 5 f ; 21-26(M=23, S D=1.9)$ yrs.

Task: Visual three-stimulus oddball task

To make a quick button press by the right thumb to the target stimuli Stimuli:

\begin{tabular}{|c|c|c|c|c|}
\hline & \multicolumn{2}{|c|}{ Central } & \multicolumn{2}{|c|}{ Surrounding } \\
\hline & Easy & Difficult & Easy & Diffic \\
\hline
\end{tabular}

Standard $(p=.70) \quad \because \quad 0$ SOA: $1.2 \mathrm{~s}$

Viewing distance: $1 \mathrm{n}$

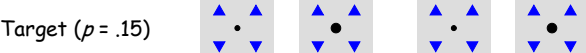

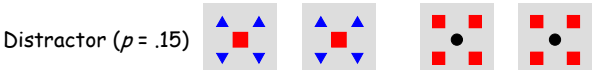

Surrounding stimuli (triangle \& square) were placed with their center $2.12^{\circ}$ to
the left and right of the vertical meridian, and $2.12^{\circ}$ above and below the horizontal meridian

ERP recording:

EEG: 30 electrode sites, referred to the nose tip
Bandpass: $0.05-100 \mathrm{~Hz}, \mathrm{AID}: 50 \mathrm{~Hz}$ (30 Hz off-line low-pass filter)
P300 peak: max. pos. pts. $300-700 \mathrm{~ms} \mathrm{at} \mathrm{PZ}$ (target), CZ (distractor)

\section{Results \& Discussion}

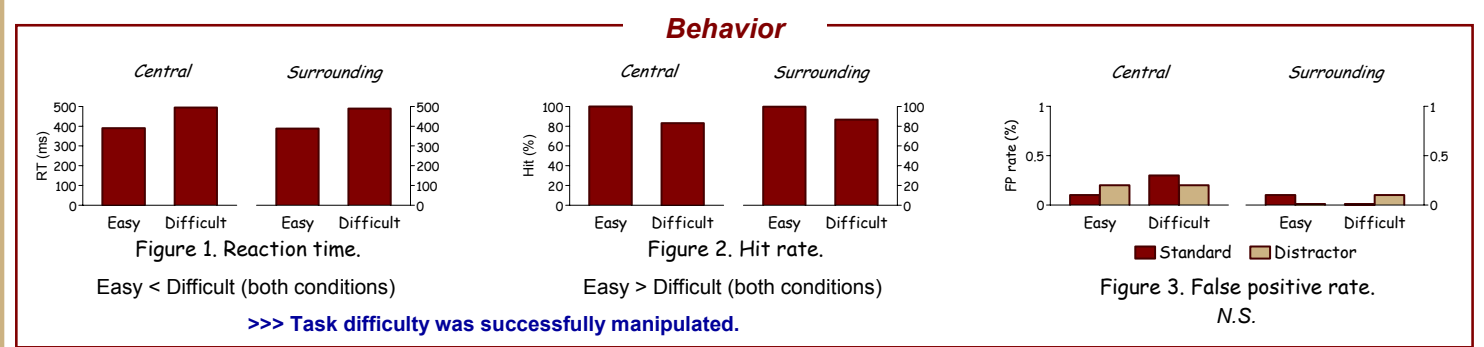

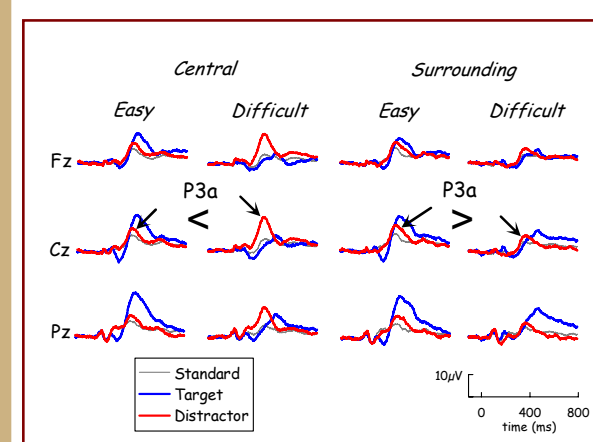

Figure 4. Grand averaged ERPs $(N=12)$

Target P3b Amplitude \& Latency: Amplitude: Easy > Difficult (both conditions)

〉> Task difficulty was successfully manipulated.

Distractor P3a Amplitude: Central condition: Easy < Difficul Surrounding condition: Easy > Difficult

》> Task difficulty had a contrasting effect on the P3a amplitude between central and surrounding conditions.

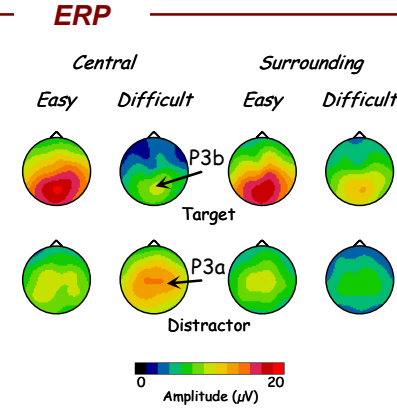
Figure 5. Topographic maps for

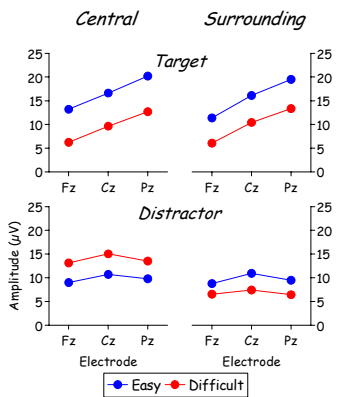

Figure 6. Mean $\mathrm{P} 3$ peak amplitude.
Top-down attentional control regulates the focus of spatial attention to detect difficult targets.

>> Focused spatial attention facilitates deviant processing inside its small focus and attenuates outside the focus.

>> Attentional capture is enhanced inside the focus whereas attentional capture is attenuated outside the focus.

$$
\begin{aligned}
& \text { Central } \\
& \text { Easy Difficult }
\end{aligned}
$$

\section{Conclusion}

Attentional capture for distractor is modulated by top-down controlled attentional focus. Acknowledgments: Risa Sawaki is now at the Center for Mind and Brain, UC Davis, 267 Cousteau Place, Davis, CA, 95618. 